\title{
Impactos ambientais e socioeconômicos da produção integrada de base ecológica em unidades de produção familiar do Distrito Federal e entorno
}

\author{
Environmental and socioeconomic impacts of ecologically based integrated \\ production: A case study in three family units of the Federal District and \\ surrounding
}

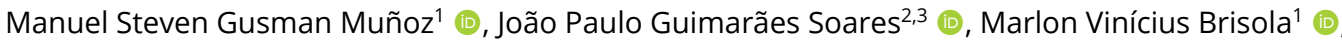 \\ Ana Maria Resende Junqueira' ${ }^{1}$,, Maria Julia Pantoja ${ }^{1}$ (i)

\begin{abstract}
1Programa de Pós-graduação em Agronegócios (PROPAGA), Faculdade de Agronomia e Medicina Veterinária (FAV), Universidade de Brasília (UnB), Brasília (DF), Brasil. E-mails: maguzmu@hotmail.com; mvbrisola@gmail.com; anajunqueiraunb@gmail.com; jpantoja@unb.br

${ }^{2}$ Programa de Pós-graduação em Agronegócios (PROPAGA), Universidade de Brasília (UnB), Planaltina (DF), Brasil. E-mail: jp.soares@embrapa.br
\end{abstract} \\ ${ }^{3}$ Empresa Brasileira de Pesquisa Agropecuária (Embrapa Cerrados), Planaltina (DF), Brasil.
}

Resumo: O trabalho analisou os impactos ambientais e socioeconômicos da produção integrada de base ecológica, considerando a sustentabilidade em longo prazo das atividades de produção vegetal e da criação animal nas unidades produtivas. Para esse fim, foram avaliadas três unidades agropecuárias familiares, denominadas "A", "B" e "C", localizadas na Região Integrada de Desenvolvimento do Distrito Federal e Entorno (RIDE-DF). Nessas unidades, foi aplicado o Sistema de Avaliação Ponderada de Impacto Ambiental de Atividades do Novo Rural (APOIA-Novo Rural), o qual contempla cinco dimensões de sustentabilidade: (a) Ecologia da paisagem, (b) Qualidade dos compartimentos ambientais (atmosfera, água e solo), (c) Valores socioculturais, (d) Valores econômicos e (e) Gestão e Administração. No sistema, o Índice de Sustentabilidade da Atividade é definido por uma linha de adequação ambiental, estipulada em 0,70 (em uma escala de 0 a 1). A produção integrada de base ecológica das três unidades avaliadas gerou desempenhos positivos no Índice Médio de Sustentabilidade $(0,74)$, com destaque para as dimensões Gestão e Administração $(0,88)$ e Ecologia da Paisagem $(0,79)$. Embora o resultado global tenha sido positivo, a análise apontou a necessidade de investimentos na variável solo sob manejo orgânico.

Palavras-chave: agroecologia, produção orgânica, índice de sustentabilidade, APOIA-Novo Rural.

\begin{abstract}
The work analyzed the environmental and socioeconomic impacts of integrated ecological production, considering the long-term sustainability of plant production and animal husbandry activities. For this purpose, three family farming units, called " $\mathrm{A}$ ", " $\mathrm{B}$ " and " $\mathrm{C}$ ", located in the Integrated Region of the Federal District and Surroundings (RIDE - DF), were evaluated. In these units, the Weighted Environmental Impact Assessment System for Novo Rural Activities (APOIA-Novo Rural) was applied, which includes five dimensions of sustainability: (a) Landscape ecology; (b) Quality of the environmental compartments (atmosphere, water, and soil); (c) Sociocultural values; (d) Economic values and (e) Management and Administration. In the system, the Activity Sustainability Index is defined by an environmental adequacy line, set at 0.70 (on a scale of 0 to 1). Ecologically based integrated production of the three units generated positive performances in the average sustainability index (0.74), with emphasis on the Management and Administration (0.88) and Landscape Ecology (0.79) dimensions. Although the overall result was positive, the analysis pointed to the need for investments in the variable soil under organic management.
\end{abstract}

Keywords: agroecology, organic production, sustainability index, APOIA-Novo Rural. 
Introdução

A adoção de práticas complementares entre produção vegetal e criação animal esteve presente no desenvolvimento dos sistemas agrícolas desde os tempos mais remotos (Mazoyer \& Roudart, 1998). Lima (2009) destaca que foi justamente essa integração que permitiu alcançar um salto tecnológico na agricultura, o que se fundamentou em aproveitar os vínculos entre os organismos produtores de biomassa nos agroecossistemas (vegetais) e os organismos consumidores (animais). Esse fato desencadeou um melhoramento significativo na quantidade e qualidade dos alimentos produzidos.

Em conformidade com Freire et al. (2009), além de proporcionar diversidade de provisões, com alta qualidade nutricional para a alimentação humana, os animais cumprem outras funções, gerando insumos fundamentais para o avanço dos sistemas agrícolas, abastecendo uma cota importante dos requerimentos alimentares que os retroalimentam.

Não obstante, essa prática integradora sofreu uma forte ruptura em meados do século passado, motivada pelo fenômeno denominado de 'Revolução Verde', a qual trouxe a possibilidade de adubar os solos com fertilizantes sintéticos, o que, somado à motomecanização, gerou a desarticulação ecológica entre as culturas e as criações, tornando os sistemas produtivos - tanto os vegetais, quanto os animais - mais especializados e mais isolados um do outro (Lima, 2009).

Vale considerar que os estudos sobre integração animal-vegetal, como prática sustentável, começaram a partir da década de 1920, época na qual surgiram as primeiras vertentes de produção alternativa, nas quais, além da mencionada integração, esses sistemas produtivos eram importantes para as práticas da adubação verde e da rotatividade de culturas (Rezende, 2005). Dessa maneira, a diversidade e as inter-relações solo-planta-animal converteram-se em conceitos-chave, pois visavam a associação e a interação dos animais com os policultivos, anuais ou perenes, fazendo com que existisse tanto a maior oferta de produtos, quanto maiores fontes de renda (Brisola, 2001; Empresa Brasileira de Pesquisa Agropecuária, 2012).

Tosetto et al. (2013) determinam três fatores fundamentais para o cuidado sob manejo ecológico de animais nas unidades familiares, sendo eles: (1) a produção de esterco, o qual permite a sustentabilidade econômica e orgânica do sistema ao restringir a aquisição de fertilizantes químicos, ao mesmo tempo em que resguarda a propriedade de fontes externas da adubação natural, que podem apresentar resquícios de agrotóxicos; (2) a diversidade na produção, devido ao fato de que os produtos de origem animal possuem um alto grau de proteínas e contribuem na segurança alimentar da família, além de gerar renda, por meio da venda dos excedentes, e (3) a oferta de serviço por parte dos animais, considerados como promotores de um significativo auxílio na prática das lavouras, no dia a dia, convertendo-se em um tipo de força de trabalho complementar.

Levando-se em consideração as exigências cada vez maiores na qualidade dos produtos e na segurança alimentar, no bem-estar da sociedade e na sustentabilidade do meio ambiente em geral, tem se tornado necessária a implementação de modos de produção alternativos aos sistemas convencionais, nos quais se enquadram a produção integrada como importante atividade a ser considerada, especialmente nos últimos tempos (Aguiar et al., 2005).

Tendo-se em conta o exposto, torna-se fundamental constituir um meio para a realização de técnicas de alcance dessa sustentabilidade produtiva, aliadas a meios de se fazer uma ponderação das atividades do referido modelo de produção, com o propósito de realizar uma adequada gestão ambiental dos estabelecimentos rurais. Dessa forma, propiciar a participação efetiva dos produtores no processo de avaliação da mesma, por meio do estudo de tecnologias mais apropriadas para o trabalho agrícola e da aplicação de parâmetros de sustentabilidade, fundamentados em critérios viáveis mostra-se uma iniciativa interessante.

Neste sentido, propõe-se, neste estudo, a aplicação de método para avaliação do desempenho ambiental das atividades rurais por meio do sistema de Avaliação de Impacto Ambiental (AIA), o qual representa uma análise dos aspectos sociais, culturais, econômicos e ecológicos para fim de comparação, por meio de sua mensuração (Rodrigues et al., 2006). Buscou-se, assim, analisar a sustentabilidade de três estabelecimentos familiares que dispõem da produção integrada de base ecológica na região rural do Distrito Federal e Entorno, como forma demonstrativa e comparada, com o fito de mensurar os impactos ambientais e as repercussões socioeconômicas do processo de integração da produção animal e vegetal.

A análise de impactos ambientais foi feita por meio do Sistema de Avaliação Ponderada de Impacto Ambiental de Atividades do Novo Rural (APOIA-Novo Rural), uma ferramenta de Avaliação de Impacto Ambiental constituída por um conjunto de 62 indicadores, incorporados 
em cinco dimensões de sustentabilidade: (1) Ecologia da paisagem, (2) Qualidade dos compartimentos ambientais (atmosfera, água e solo), (3) Valores socioculturais, (4) Valores econômicos e (5) Gestão e administração (Rodrigues et al., 2008). O APOIA-Novo Rural apresenta-se como uma opção adequada ao que se propõe, uma vez que fornece informações concretas ao produtor acerca da situação socioambiental do seu estabelecimento e de sua atividade, possibilitando ações de melhoramento no curto prazo.

\section{Orientações sobre o Sistema de Avaliação de Impacto Ambiental e o Método de Pesquisa}

A implementação de um novo padrão de produção e gestão no empreendimento não abrange somente âmbitos técnicos, produtivos e ecológicos, mas também permite compreender elementos socioculturais intrínsecos ao agricultor, à sua família e à sua comunidade (Marzall \& Almeida, 2000). Por conseguinte, requer a avaliação dos impactos ocasionados pelas novas práticas de manejo, tanto no meio ambiente quanto nos critérios sociais e econômicos, salientando as mudanças geradas a partir de seu emprego no estabelecimento rural (Rodrigues et al., 2006).

É importante acrescentar que, no momento de avaliar os impactos de uma tecnologia de produção, considera-se desejável abarcar um conjunto de indicadores que sejam capazes de demonstrar o aporte dessa inovação, mensurando o seu desempenho (Rodrigues et al., 2003).

Neste sentido, o desempenho ambiental das atividades rurais - objeto da Avaliação de Impacto Ambiental (AIA) por meio da análise conjunta de aspectos sociais, culturais, econômicos e ecológicos - implica em uma necessidade atendida pelo Sistema APOIA-Novo Rural, descrito anteriormente e demonstrado na Figura 1.

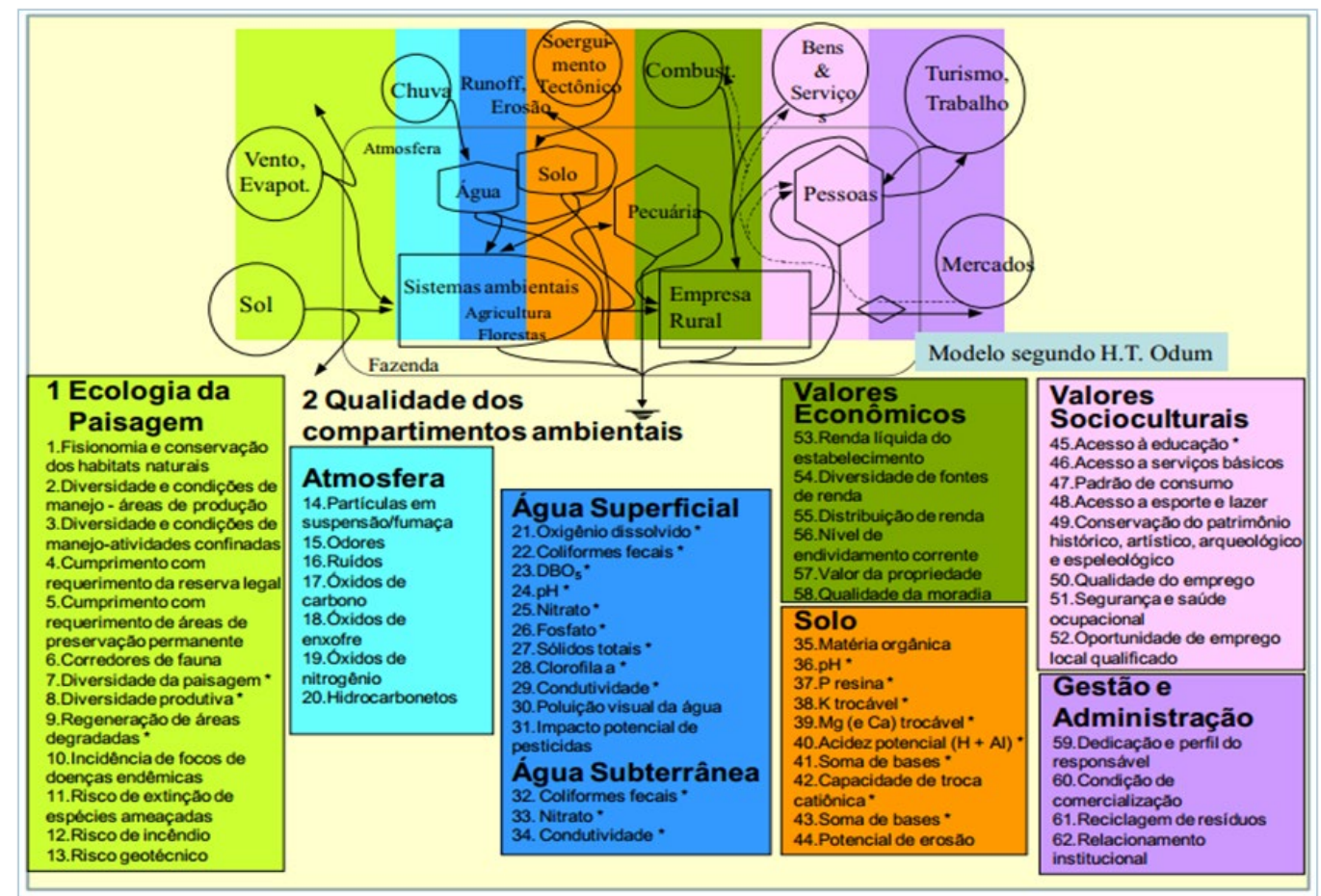

Figura 1 - Dimensões e indicadores de sustentabilidade adotados pelo sistema APOIA-Novo Rural. Fonte: Rodrigues (2011).

A avaliação do impacto ambiental da atividade rural, por meio do sistema APOIA-Novo Rural, orienta uma gestão ambiental participativa, na qual o proprietário do estabelecimento e sua família cumprem um papel fundamental, no sentido de cooperar para melhorar as dimensões e os índices com pontuações baixas. Isto é devido ao fato de o sistema fornecer a informação necessária por meio de indicadores e gráficos, os quais facilitam o entendimento do panorama apresentado na propriedade. 
Além disso, o sistema pode ser útil para sustentar a obtenção de certificações comerciais, tais como a "produção sustentável" ou a "produção orgânica", visto que, de certa forma, exerce um monitoramento sobre a maneira de produzir do estabelecimento analisado. Rodrigues \& Campanhola (2003) determinam que, com a utilização dessa ferramenta, é possível fazer uma análise comparativa da situação prévia e posterior à implementação da produção integrada de caráter ecológico. Além disso, é possível obter fatores de ponderação para cada causa estudada, níveis de dano dos impactos e suas escalas de variação percentual.

Os resultados da avaliação, por meio do APOIA-Novo Rural, são obtidos com base na ponderação de cada um dos 62 indicadores analisados em uma planilha de AIA da atividade rural. Isso permite estabelecer o desempenho ambiental da propriedade, tendo em conta que cada indicador é convertido automaticamente em um valor de utilidade, que tem uma pontuação de 0 até 1,0 , e que a linha base estabelecida, que determina uma performance favorável, corresponde a 0,70 (Rodrigues et al., 2006).

Cabe destacar que, para a obtenção dos índices de alguns indicadores pertencentes à dimensão Qualidade dos Compartimentos Ambientais, no concernente à água e ao solo, é necessária coleta de amostras para seu posterior estudo em laboratório, sendo este utilizado para o preenchimento no sistema dos dados obtidos dessa análise. Em relação aos indicadores relacionados com os aspectos socioeconômicos, é levado em consideração o conhecimento dos proprietários sobre suas unidades. Uma vez ponderados os 62 indicadores nas cinco dimensões de sustentabilidade, é obtido um valor médio geral, correspondente ao índice de impacto ambiental da atividade rural do estabelecimento.

Os resultados da avaliação são apresentados em uma planilha de AIA da atividade rural, o que permite obter uma expressão gráfica para cada dimensão, possibilitando, por sua vez, averiguar o desempenho da atividade para cada indicador, em comparação com a linha base estabelecida (Campanhola et al., 2004, p. 281).

As dimensões e os indicadores que compõem o Sistema APOIA-Novo Rural, bem como as unidades de medida consideradas tanto em campo quanto em laboratório, podem ser observados na Tabela 1.

Tabela 1 - Dimensões e indicadores de impacto ambiental do sistema APOIA-Novo Rural e unidades de medida utilizadas para caracterização em levantamentos de campo e laboratório

\begin{tabular}{|c|c|}
\hline Dimensões e indicadores & $\begin{array}{c}\text { Unidades de medida obtidas no campo e } \\
\text { laboratório }\end{array}$ \\
\hline \multicolumn{2}{|c|}{ Dimensão Ecologia da Paisagem } \\
\hline Fisionomia e conservação dos habitats naturais & Porcentagem da área da propriedade \\
\hline $\begin{array}{l}\text { Diversidade e condições de manejo das áreas de } \\
\text { produção }\end{array}$ & Porcentagem da área da propriedade \\
\hline $\begin{array}{l}\text { Diversidade e condições de manejo das } \\
\text { atividades confinadas (agrícolas/não-agrícolas e } \\
\text { de confinamento animal) }\end{array}$ & $\begin{array}{l}\text { Porcentagem da renda da propriedade, } \\
\text { excluídas atividades não confinadas }\end{array}$ \\
\hline \multicolumn{2}{|l|}{$\begin{array}{l}\text { Cumprimento com requerimento da reserva } \\
\text { legal }\end{array}$} \\
\hline $\begin{array}{l}\text { Cumprimento do requerimento de áreas de } \\
\text { preservação permanente }\end{array}$ & $\begin{array}{l}\text { Porcentagem da área averbada como reserva } \\
\text { legal na propriedade }\end{array}$ \\
\hline Corredores de fauna & Porcentagem da área da propriedade \\
\hline Diversidade da paisagem ${ }^{(1)}$ & Área (ha) e número de fragmentos \\
\hline Diversidade produtiva ${ }^{(1)}$ & Índice de Shannon-Wiener (dado) \\
\hline Regeneração de áreas degradadas ${ }^{(1)}$ & Índice de Shannon-Wiener (dado) \\
\hline Incidência de focos de doenças endêmicas & Porcentagem da área da propriedade \\
\hline Risco de extinção de espécies ameaçadas & Número de criadouros \\
\hline Risco de incêndio & $\begin{array}{l}\text { Número de número de populações e } \\
\text { subpopulações ameaçadas }\end{array}$ \\
\hline \multirow[t]{2}{*}{ Risco geotécnico } & Porcentagem da área atingida pelo risco \\
\hline & Número de áreas influenciadas \\
\hline
\end{tabular}


Tabela 1 - Continued..

\section{Dimensão Qualidade dos Compartimentos Ambientais}

\section{Atmosfera}

Partículas em suspensão/fumaça

Odores

Ruídos

Óxidos de carbono

Óxidos de enxofre

Óxidos de nitrogênio

Hidrocarbonetos

Porcentagem do tempo de ocorrência

Porcentagem do tempo de ocorrência

Porcentagem do tempo de ocorrência

Porcentagem do tempo de ocorrência

Porcentagem do tempo de ocorrência

Porcentagem do tempo de ocorrência

Porcentagem do tempo de ocorrência

\section{Água superficial}

Oxigênio dissolvido (1)

Porcentagem de saturação de $\mathrm{O}_{2}$

Coliformes fecais ${ }^{(1)}$

Número de colônias/100 ml

$\mathrm{DBO}_{5}{ }^{(1)}$

Miligrama/L de $\mathrm{O}_{2}$

$\mathrm{pH}^{(1)}$

$\mathrm{pH}$

Nitrato ${ }^{(1)}$

Fosfato (1)

Sólidos totais ${ }^{(1)}$

Clorofila a ${ }^{(1)}$

Condutividade

Poluição visual da água

Impacto potencial de pesticidas

Miligrama de $\mathrm{NO}_{3} / \mathrm{L}$

Miligrama $\mathrm{P}_{2} \mathrm{O}_{5} / \mathrm{L}$

Miligrama sólidos totais/L

Micrograma clorofila/L

Micro ohm/cm

Porcentagem do tempo de ocorrência

Porcentagem da área tratada

\section{Água subterrânea}

Coliformes fecais (1)

Número de colônias/100 ml

Nitrato ${ }^{(1)}$

Miligrama de $\mathrm{NO}_{3} / \mathrm{L}$

Condutividade (1)

Micro ohm/cm

\section{Manutenção da capacidade produtiva do solo}

Matéria orgânica

$\mathrm{pH}^{(1)}$

P resina ${ }^{(1)}$

K trocável ${ }^{(1)}$

Mg (e Ca) trocável (1)

Acidez potencial $(\mathrm{H}+\mathrm{Al})^{(1)}$

Soma de bases ${ }^{(1)}$

Capacidade de troca catiônica ${ }^{(1)}$

Volume de bases ${ }^{(1)}$

Potencial de erosão
Porcentagem de matéria orgânica

$\mathrm{pH}$

Miligrama $\mathrm{P} / \mathrm{dm}^{3}$

Milimol de carga/dm ${ }^{3}$

Milimol de carga/dm ${ }^{3}$

Milimol de carga/dm ${ }^{3}$

Milimol de carga/dm ${ }^{3}$

Milimol de carga/dm ${ }^{3}$

Porcentagem de saturação

Porcentagem da área

\section{Dimensão Valores Socioculturais}

Acesso à educação (1)

Acesso a serviços básicos

Padrão de consumo

Acesso a esporte e lazer

Conservação do patrimônio histórico, artístico, arqueológico e espeleológico

Qualidade do emprego

Oportunidade de emprego local qualificado
Número de pessoas

Acesso a serviços básicos (1 ou 0)

Acesso a bens de consumo ( 1 ou 0 )

Horas dedicadas

Número de monumentos/eventos do patrimônio

Porcentagem dos trabalhadores

Porcentagem do pessoal ocupado 


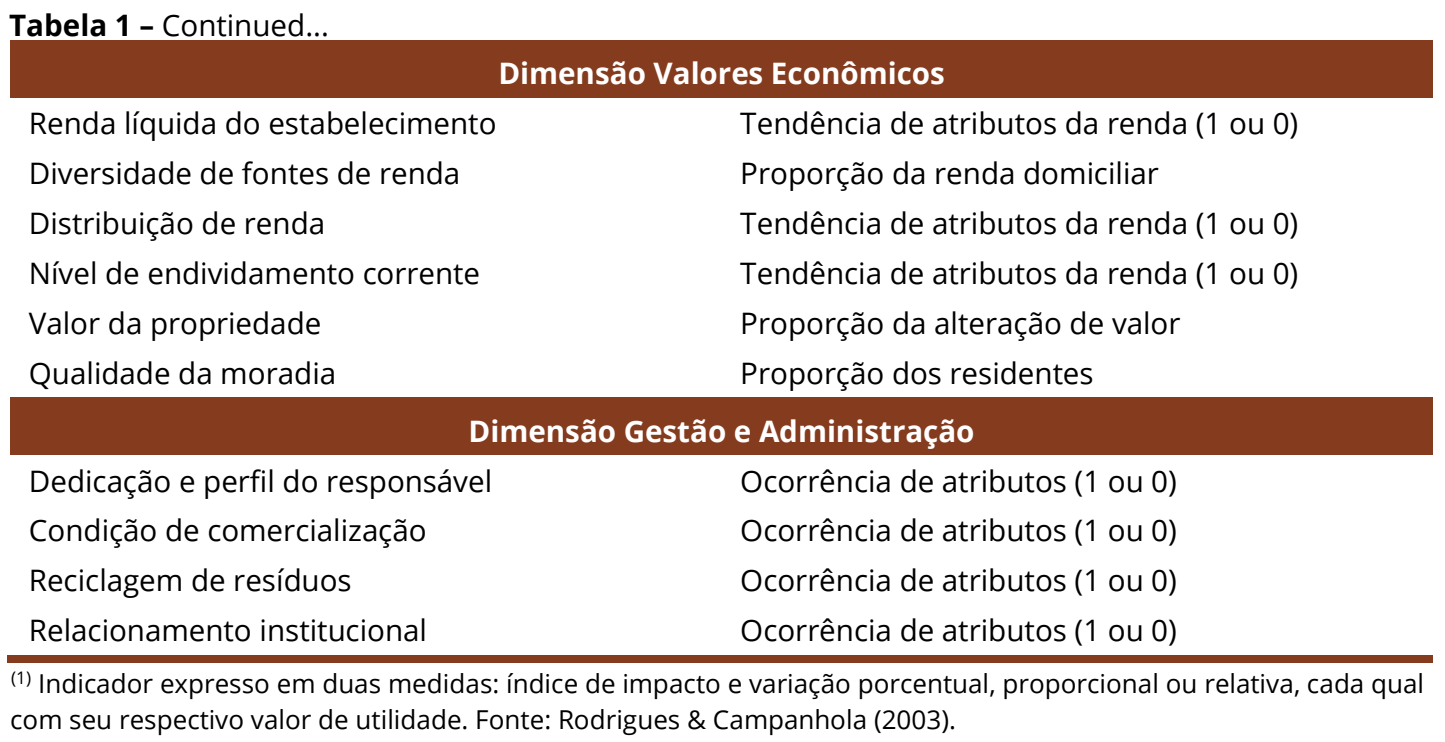

A aplicação do Sistema Apoia-Novo Rural no referido estudo procedeu-se em três unidades de Agricultura Familiar com produção integrada de base ecológica, localizadas no Distrito Federal e Região Integrada de Desenvolvimento do Distrito Federal e Entorno (RIDEDF).

Dois dos estabelecimentos avaliados se encontram no Distrito Federal (A e B), nas Regiões Administrativas ${ }^{1}$ (RAs) de Taguatinga e Sobradinho, respectivamente. O terceiro (C) está localizado no município de Santo Antônio do Descoberto-GO, que compõe a RIDE-DF.

Para selecionar os participantes do estudo, foi considerada uma amostragem intencional, levando-se em consideração os propósitos da pesquisa. Logo, foram estabelecidos os seguintes critérios de seleção: (a) que seja produtor orgânico certificado em pelo menos uma das atividades (produção vegetal ou criação animal), (b) que a propriedade se localize dentro dos limites da RIDE-DF, (c) que possua as características representativas da Agricultura Familiar, (d) que apresente em suas atividades a integração animal-vegetal e (e) que seja unidade de referência para a produção orgânica ou em processo de transição orgânica na região.

\section{Resultados e Discussão}

De maneira geral, as três propriedades analisadas pelo Sistema APOIA-Novo Rural apresentaram características similares em relação ao aproveitamento máximo dos recursos disponíveis em seus estabelecimentos. Isso decorre do fato de as práticas agrícolas, pecuárias e agroindustriais, adotadas em todas as unidades produtivas, obedecerem a uma lógica em favor da sustentabilidade.

Essas ações concretas - resumidas na otimização do espaço, no uso de tecnologias agroecológicas, no consumo de alimentos com um alto valor nutricional, produzidos no interior de suas unidades, e na comercialização ética e responsável - contribuem com produtos de ótima qualidade. Em suma, cada uma das iniciativas consideradas no estudo trabalha pela melhoria das condições sociais, econômicas e ambientais de suas áreas.

A seguir, são apresentadas as características das unidades e apresentados os resultados alcançados, por meio da avaliação de impactos para cada uma delas.

\section{Unidade A}

Está situada na RA de Taguatinga-DF, no núcleo rural dessa localidade. Taguatinga tem 56 estabelecimentos rurais no total e 27 com produção familiar, sendo 45 estabelecimentos

\footnotetext{
1 O Distrito Federal não possui municípios ou bairros. A área total é subdividida em Regiões Administrativas (RAs) que
} possuem gestão própria, submetidas à gestão do Governo do Distrito Federal 
com área inferior a 20 ha. A região administrativa situa-se a oeste do Distrito Federal, ocupando uma área total de $81 \mathrm{~km}^{2}$. Possui população de 199.715 habitantes, dos quais 198.350 habitam em área urbana e 1.365 na área rural, distribuídos em chácaras das seis colônias agrícolas e dos dois núcleos rurais (Companhia de Planejamento do Distrito Federal, 2015). No setor primário, destacam-se os hortifrutigranjeiros com vistas ao abastecimento interno do Distrito Federal, sendo a CEASA/DF o principal destino destes produtos.

A unidade A possui um importante número de espécies vegetais de pequeno e médio porte, distribuídas em hortaliças (beterraba, berinjela, cebola, nabo, alho, entre outras) e frutas (abacate, mamão, pepino, tomate, limão, laranja, goiaba, banana, acerola, entre outras). O estabelecimento se tornou produtivo em 2002, ano de obtenção da certificação orgânica para produtos de origem vegetal, ao redor de 25 itens. Nem todos eles, porém, são de origem vegetal, pois, com o propósito de fechar o ciclo dos resíduos gerados nos canteiros, foram introduzidas galinhas para a produção ecológica de ovos a partir de 2008.

$\mathrm{Na}$ dimensão Ecologia da Paisagem, a unidade A tem destaque nos indicadores relacionados com o Cumprimento dos Requerimentos da Reserva Legal (índice $=0,94$ ), sendo que a extensão destinada para esse propósito possui dimensões superiores às estabelecidas no Novo Código Florestal, que é de $20 \%$ da propriedade.

Na dimensão Diversidade e Condições de Manejo das Atividades Confinadas (índice = 0,92), ressaltam-se as boas condições das instalações para criação de galinhas caipira e o cumprimento do requerimento de Áreas de Preservação Permanente - APP (índice = 0,91). Esses resultados são respaldados pela melhoria das condições de preservação da área de cerrado na propriedade, assim como em virtude da troca de nutrientes pela integração das atividades animais e vegetais. O restante dos indicadores, igualmente, apresentou índices acima da linha base, em que o desempenho da unidade nessa dimensão foi satisfatório (índice = 0,81).

Quanto à dimensão Qualidade dos Compartimentos Ambientais, observaram-se valores positivos nos componentes atmosfera e água, salientando-se que, no caso dessa unidade, o recurso hídrico é obtido de maneira subterrânea. Observaram-se índices satisfatórios nos indicadores de Coliformes Fecais (índice $=1$ ), Nitrato (índice $=1$ ) e Condutividade da Água (índice $=0,95$ ), apresentando-se como de excelentes condições.

No entanto, o componente solo teve um comportamento insatisfatório, uma vez que só quatro dos dez indicadores alcançaram índices acima ou iguais à linha base, sendo eles a Matéria Orgânica (índice $=0,93$ ), o Potencial Hidrogeniônico $(\mathrm{pH}$ ) (índice =0,99), a Acidez Potencial (índice $=0,78$ ) e o Potencial de Erosão (índice $=0,70$ ). Os demais indicadores, relacionados com os elementos químicos essenciais $\mathrm{P}, \mathrm{Mg}, \mathrm{K}$ e suas inter-relações, necessárias para um adequado desempenho agrícola, apresentaram índices muito baixos.

Os indicadores que alcançaram melhores índices estão relacionados ao manejo de integração utilizado nessa Unidade. A utilização dos resíduos provenientes da produção das aves pelo manejo integrado dos animais nas áreas de preservação permanente reafirma os ganhos ambientais e produtivos, com a incorporação de matéria orgânica e a correção da acidez (Soares et al., 2014), além de melhoria da estrutura dos solos (Soares et al., 2018). Galharte (2007), ao avaliar os impactos ambientais da integração lavoura-pecuária, observou que a maior cobertura do solo contribui para a redução da erosão e da perda de matéria orgânica e de nutrientes. A presença da vegetação nativa favorece a agregação de partículas do solo, o que colabora para a diminuição da erosão e melhora a estrutura do solo, proporcionando maior porosidade (Macedo, 2009).

No que concerne à dimensão Valores Socioculturais, sobressaíram os indicadores Segurança e Saúde Ocupacional (índice $=0,96$ ), fundamentados pelo manejo ecológico da unidade, o qual determina fatores de risco menores, e a Oportunidade de Emprego Local Qualificado (índice $=0,97$ ), relacionado com a facilidade de encontrar mão de obra capacitada 
perto da propriedade. Os demais indicadores apresentaram-se iguais ou superiores à linha base, determinando um índice de impacto para a dimensão de 0,81.

Em relação à dimensão Valores Econômicos, destacaram-se os indicadores associados ao Valor da Propriedade (índice = 1), o que está baseado em elementos internos, como as benfeitorias feitas na unidade, e em elementos externos, como a valorização imobiliária evidenciada na região, e Qualidade da Moradia (índice =0,85). Nesse sentido, foi possível corroborar o adequado estado das instalações, incluindo os locais destinados para habitação dos trabalhadores, bem como as condições de amplitude que esses espaços oferecem para a totalidade de integrantes que moram nos estabelecimentos. Assim, o índice para essa dimensão foi de 0,80 .

$\mathrm{Na}$ dimensão Gestão e Administração, cumpre destacar o papel dos indicadores Dedicação e Perfil do Responsável (índice $=1$ ) e Disposição de Resíduos (índice = 1). No primeiro caso, o resultado está suportado pela residência do responsável na unidade, a sua dedicação exclusiva, a capacitação dirigida à atividade, o engajamento familiar, o uso de sistema contábil e a aplicação de um modelo formal de planejamento.

A situação encontrada nessa dimensão sustenta o afirmado por Abramovay (1990), que destaca a relevância da produção familiar na agricultura, transformando-a num âmbito excepcional no capitalismo contemporâneo, uma vez que não se tem outra atividade econômica na qual o trabalho e a gestão confluam tão profundamente ao redor de vínculos de parentesco e em que a atuação da mão de obra não contratada seja tão significativa. É oportuno acrescentar que, no mundo todo, existem mais de 500 milhões de unidades agrícolas com características familiares e que essas unidades representam $98 \%$ de todos os empreendimentos agrícolas (Organización de las Naciones Unidas para la Alimentación y la Agricultura, 2014).

Em relação ao segundo indicador, foram constatadas ações, como a coleta seletiva, o uso de compostagem e a disposição sanitária. Da mesma maneira, os outros indicadores da dimensão ficaram acima da linha base, propiciando um índice para essa dimensão de 0,87 . As atividades socioeconômicas e ambientais desenvolvidas na unidade A constituem uma estratégia de sustentabilidade e resiliência, perante o modelo de agricultura dominante. Segundo Cavalcanti \& Maistro (2015), está determinada, pelo progressivo esgotamento do petróleo, a organização de potentes grupos econômicos, capazes de determinar cada vez mais o futuro das paisagens agrícolas, possibilitando o domínio dos sistemas alimentares e de combustíveis, e permitindo decidir o que, como e quanto produzir.

Dessa maneira, o último patamar da agricultura convencional trouxe consigo a emergência de corporações biogenéticas transnacionais, agremiações essas que estão levando a cabo uma ofensiva produtiva e comercial que, possivelmente, gerará relações de dependência agrária, genética, econômica, política, tecnológica e alimentar, ao mesmo tempo em que conduzirá categóricas transformações espaciais e econômicas no meio rural (Serrano, 2005). Consequentemente, é importante propiciar a continuidade de unidades produtivas de base ecológica, visto que estas consideram o desenvolvimento de maneira integral, levando em grande conta os aspectos ambientais, econômicos e sociais nas suas ações cotidianas.

Posicionamento este que é compartilhado por Lutzenberger (2001), que determina que o problema essencial da agricultura convencional é a sua insustentabilidade. Conforme sua análise, não é admissível abrigar esse tipo de produção só por sua suposta produtividade, pois as consequências que traz consigo em longo prazo são impactantes. Torna-se, portanto, urgente desenvolver técnicas de produção agrícola mais sustentáveis.

Nessa perspectiva, o desempenho socioambiental satisfatório da unidade A, em virtude do processo de integração animal-vegetal, pode ser demonstrada na Figura 2. A avaliação ponderada nas cinco dimensões apresentou um índice de 0,75, isto é, acima da linha base de adequação ambiental $(0,70)$. 


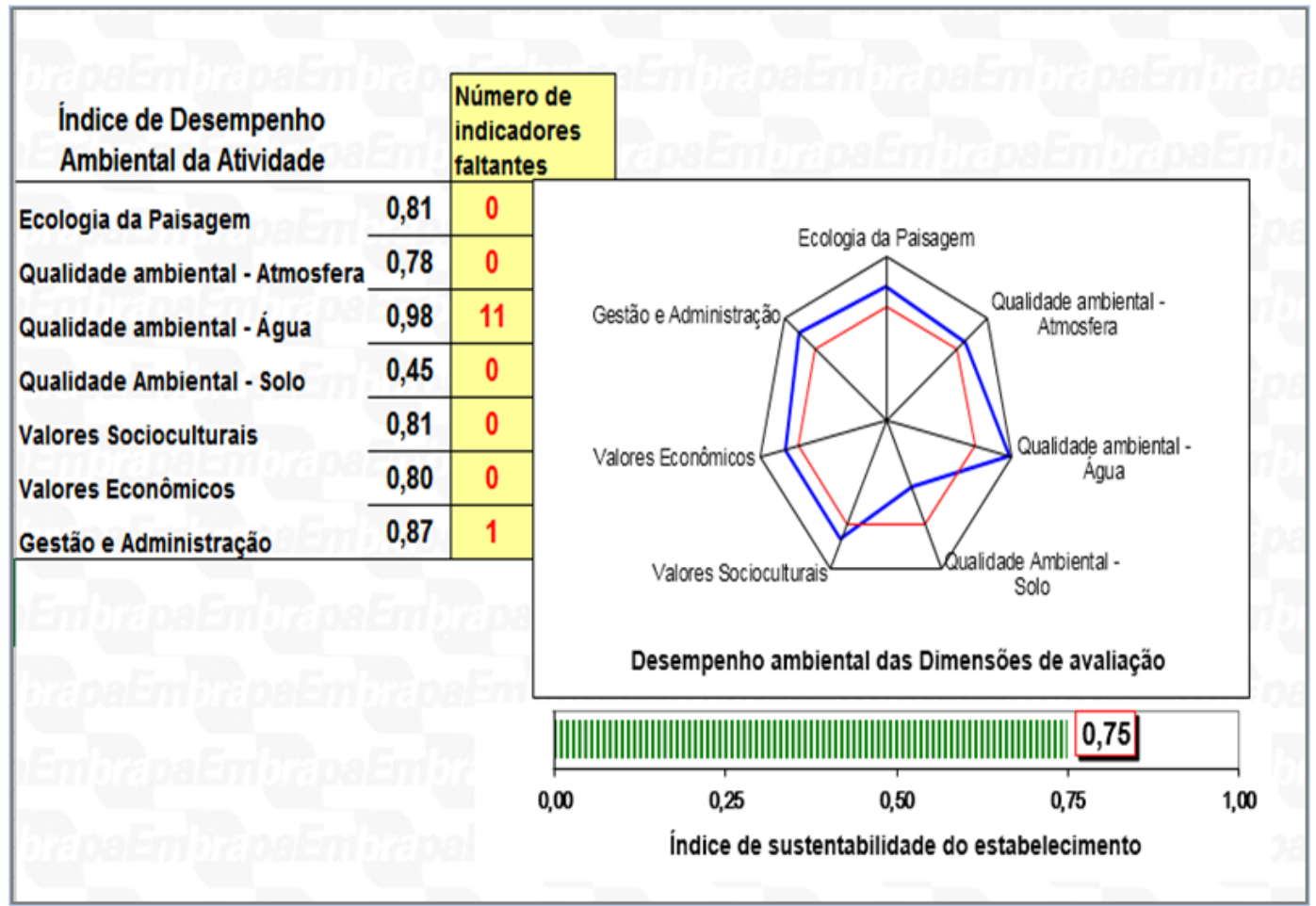

Figura 2 - AIA final por meio do Sistema APOIA-Novo Rural, Unidade A. Fonte: Extraído pelos autores do Sistema APOIA-Novo Rural (2017).

\section{Unidade B}

Esta unidade está localizada no Núcleo Rural Capão da Erva da RA Sobradinho. A Região Administrativa de Sobradinho situa-se ao norte do Distrito Federal, ocupando área total de 203,4 km², sendo os núcleos rurais com 4.750 ha e as áreas isoladas com 2.983 ha. Possui população de 60.209 habitantes, dos quais 2.339 vivem na área rural (Companhia de Planejamento do Distrito Federal, 2015). O município, em 2010, tinha 179 estabelecimentos rurais, sendo 67 com produção familiar e 83 com área inferior a 20 ha. O setor primário de Sobradinho participa com 9,72\%, 10,46\% e 5,89\%, respectivamente, da produção de ovos, leite e carne do DF.

A unidade B caracteriza-se como tipicamente familiar. Sobressai-se pela abundância de atividades agrícolas, pecuárias e agroindustriais, todos elas realizadas em uma área relativamente pequena (4 ha). Assim, a diversidade de atividades, próprias da agricultura familiar e da produção orgânica presentes nesse local, contrapõe-se com o modelo de agricultura industrial. Conforme González de Molina (2004), a agricultura industrial é insustentável e reducionista, pois prioriza o cultivo de monoculturas transgênicas em áreas de extensão cada vez maiores e termina por submeter os agricultores a caros pacotes tecnológicos, compostos por sementes patenteadas e agroquímicos.

Dessa maneira, a unidade B é um exemplo de como a produção familiar pode restabelecer as relações harmônicas entre o homem e o meio natural em que vive, diminuindo o impacto de suas atividades agrícolas no ambiente, ampliando, desse modo, os benefícios para além do espaço rural e gerando assim características superiores para os seus produtos, em comparação aos produtos obtidos mediante outro tipo de produção, opinião essa compartilhada por Model et al. (2015).

$\mathrm{Na}$ atualidade, o carro-chefe desse estabelecimento é a agroindústria da goiabada, a qual abrange desde a produção da matéria-prima essencial (300 pés de goiaba sob manejo orgânico) até a embalagem do produto final. Além da atividade em destaque, a propriedade contempla, desde sua constituição, em 1995, a criação de diversos animais, tais como patos, cabras, peixes e galinhas tipo caipira, sendo essa última a atividade mais representativa, com cerca de 500 aves. 
A performance da Ecologia da Paisagem (índice de impacto $=0,71$ ) nessa unidade esteve afetada pela não averbação do cumprimento de Reserva Legal, circunstância que a levou à obtenção de um índice igual a zero, nesse indicador. Contudo, constatou-se que a propriedade cumpre com o estipulado no Novo Código Florestal, que determina que, em unidades com tamanho inferior a quatro módulos fiscais, como o caso da propriedade em análise, a Reserva Legal pode estar constituída pela conservação de árvores frutíferas, ornamentais, industriais ou exóticas. De forma similar ao acontecido na unidade $A, O$ indicador com melhor desempenho nessa dimensão foi o concernente à Diversidade e Condições de Manejo das Atividades Confinadas (índice $=0,93$ ), respaldado pelas adequadas condições do estabelecimento, tanto para as práticas de criação quanto para as atividades da agroindústria.

Por outro lado, a dimensão Qualidade dos Compartimentos Ambientais apontou registros expressivos para os componentes atmosfera e água. Em relação à Atmosfera, foram obtidos índices iguais 1,0 nos indicadores Partículas em Suspensão/fumaça, Odores e Ruídos, suscitados pelas apropriadas práticas de criação animal e tratamento de resíduos adotadas na Unidade. Essas práticas diminuem a incidência dos fatores causadores de mal-estar.

No que diz respeito ao Solo, $60 \%$ dos indicadores apontaram índices abaixo da linha base, o que afetou drasticamente o desempenho geral da dimensão. Isso provavelmente ocorreu pela menor integração da produção animal e vegetal no manejo da unidade, quando pode-se identificar que os animais passavam menor tempo nas áreas de cultivo da goiaba, que eram mais afastadas, em função de exigências sanitárias da agroindústria situada na propriedade.

Do mesmo modo que na unidade $A$, a dimensão Valores Socioculturais demonstrou escores importantes nos indicadores Segurança e Saúde Ocupacional (índice $=0,96$ ) e Oportunidade de Emprego Local Qualificado (índice $=0,92$ ). Entretanto, obteve-se um índice insuficiente $(0,60)$ no indicador Acesso a Esporte e Lazer, devido à diminuição das horas semanais dedicadas ao descanso ou à prática de atividade física dos integrantes da família, desde que foram iniciadas as atividades de criação animal e produção vegetal de forma integrada. Assim, o índice de impacto para essa dimensão alcançado foi de 0,76.

No tocante à dimensão Valores Econômicos, destacaram-se igualmente os indicadores relacionados com o Valor da Propriedade (índice $=1$ ) e a Qualidade da Moradia (índice $=1$ ). Os demais indicadores demonstraram atuações satisfatórias, resultando no índice de impacto para essa dimensão de 0,83.

Na dimensão Gestão e Administração, cumpre ressaltar os indicadores Dedicação e Perfil do Responsável pela Unidade (índice = 1), Disposição de Resíduos (índice =1) e Condição de Comercialização. Esse último indicador está fundamentado pela existência de uma marca reconhecida pelos consumidores e por haver transporte próprio dos produtos, bem como a existência de um local de armazenamento de produtos dentro da propriedade. Com isso, o índice de impacto dessa dimensão alcançou o melhor comportamento nessa unidade: 0,90.

De acordo com Fonseca (2005), os consumidores cada vez mais preferem os atributos associados a um processo de produção sustentável e natural, que não utiliza agrotóxicos, que resguarda o meio ambiente e que também provê um retorno financeiro aos produtores rurais, ou seja, que prioriza, além dos aspectos agrícolas, abordagens que preservam os contextos ambientais e sociais.

Uma vez ponderados os resultados, foi possível observar que essa unidade acarreta impactos positivos em suas condições, uma vez que o índice final de impacto da atividade $(0,72)$ ficou acima da linha base, tal como verificado na Figura 3.

Levando-se em consideração o caso da Unidade B, é factível, portanto, distinguir a Agricultura Familiar como uma categoria social fundamental para superar o desafio da constituição de sistemas agroalimentares sustentáveis, que envolvam os fatores econômicos, sociais e ambientais em suas atividades, fatores esses, constituintes do chamado tripé de sustentabilidade. 


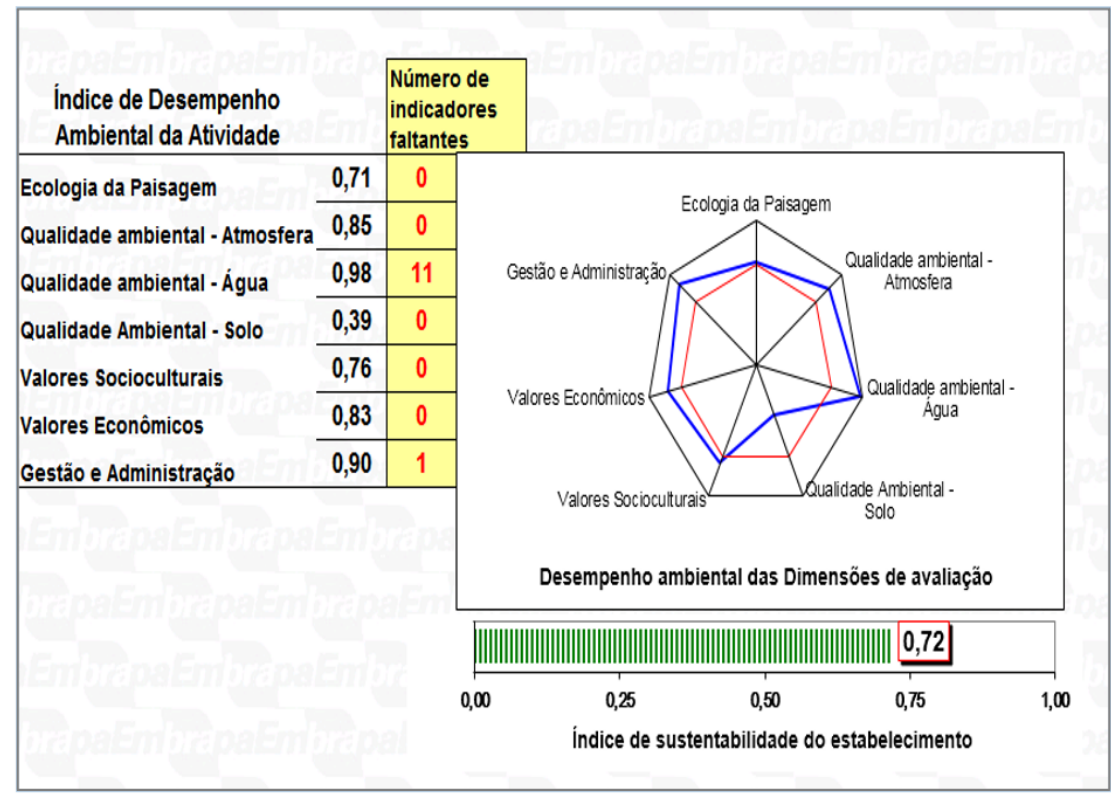

Figura 3 - AIA Final por meio do Sistema APOIA-Novo Rural, Unidade B. Fonte: Extraído pelos autores do Sistema APOIA-Novo Rural (2017).

\section{Unidade C}

Localizada no Município de Santo Antônio do Descoberto, a 70 km de Brasília-DF, no Estado de Goiás. O Município compõe a Região Integrada de Desenvolvimento do Distrito Federal e Entorno (RIDE), que abrange vários municípios do Distrito Federal e dos estados Goiás e Minas Gerais. Situado a sudoeste do estado de Goiás, o Município ocupa uma área total de 944,1 km², possui uma população de 73.023 habitantes, dos quais 6.440, na área rural (Companhia de Planejamento do Distrito Federal, 2013).

Essa propriedade apresenta-se como um espaço diversificado, em termos da quantidade de atividades agropecuárias, dentre as quais cabe destacar a produção e a comercialização de frango orgânico, bem como a agroindústria de café, a partir dos fundamentos da agricultura orgânica.

As atividades tiveram início em 2012. Inicialmente, foram desenvolvidas práticas de criação de gado convencional, as quais temporariamente produziram a homogeneização e a deterioração da paisagem. Na atualidade, ainda persistem algumas poucas cabeças de gado, manejadas de forma ecológica e aproveitadas para a obtenção de leite.

A dimensão Ecologia da Paisagem para a Unidade $C$ registrou índices elevados nos indicadores concernentes com a diminuição dos Riscos Geotécnicos (índice $=0,92$ ), devido ao não emprego de motomecanização em grande escala, ao uso de cercas vivas no entorno da propriedade e à preservação da cobertura do solo, ações que atenuam situações de inundação, deslizamento e desmoronamento das áreas. O índice de impacto da dimensão foi muito bom $(0,84)$, respaldado pelos outros indicadores, todos eles localizados acima da linha base.

Nessa ordem de ideias, o fator ambiental é favorecido pela prática da agricultura orgânica. A Organización de las Naciones Unidas para la Alimentación y la Agricultura (2003) estabelece que o bom manejo deste tipo de agricultura gera condições ambientais favoráveis, uma vez que diminui o esgotamento dos recursos naturais (solo, água, energia, nutrientes), contribui de maneira positiva para a melhoria dos problemas relacionados com a mudança climática e coopera para a conservação da biodiversidade, em uma escala global.

A dimensão Qualidade dos Compartimentos Ambientais foi afetada pelos indicadores do solo, da mesma maneira que nas Unidades A e B, considerando os únicos indicadores acima da linha base aqueles relacionados com a Matéria Orgânica Disponível (índice =0,99) e a Acidez $(0,99)$.

No que se refere à dimensão Valores Socioculturais, o indicador mais destacado foi o tocante à Segurança e Saúde Ocupacional (índice $=0,93$ ), relativo ao manejo sob condições de bem-estar e produção orgânica, para todos os componentes da unidade, incluindo os 
proprietários e trabalhadores. Adicionado a isso, os outros indicadores perfizeram índices adequados (acima da linha base), viabilizando a obtenção de um índice de impacto para essa dimensão de 0,76.

Buainain (2006) relata ser a agricultura familiar o principal segmento ofertante de alimentos orgânicos no Brasil. Corroborando com essa informação, a Secretaria Especial de Agricultura Familiar e do Desenvolvimento Agrário do Governo Federal aponta que aproximadamente $75 \%$ dos produtores registrados no Cadastro Nacional de Produtores Orgânicos (CNPO) são agricultores familiares (Brasil, 2017). Para esses agricultores, práticas habituais do processo agroecológico, como a diversificação da produção e a independência de insumos externos, são muito proveitosas, pois resulta em estabilidade de renda durante o ano todo e na maior facilidade no manejo dos recursos da propriedade (Castro Neto et al., 2010).

De forma similar ao acontecido nas unidades anteriores, o indicador com melhor desempenho na dimensão Valores Econômicos foi a qualidade da moradia, com um índice de 0 ,83. Por outro lado, registrou-se um índice insatisfatório $(0,53)$ no indicador Renda Líquida do Estabelecimento, devido à detecção de baixa ou ausência de margem econômica na atividade de criação de frango orgânico, ainda requerente de investimentos. Contudo, uma vez ponderados os demais indicadores, o índice de impacto para essa dimensão foi favorável $(0,76)$. Nesta sequência e em conformidade com Campanhola e Valarini (2001, p.76), a agricultura orgânica representa uma significativa oportunidade de renda para os pequenos agricultores, por causa da crescente demanda mundial por alimentos saudáveis.

Por fim, a dimensão Gestão e Administração assinalou atuações consideráveis nos indicadores Dedicação e Perfil do Responsável (índice = 1) e Disposição de Resíduos (índice = 1). Nesse sentido, destaca-se que essa unidade produz a totalidade do adubo orgânico requerido para suas atividades agrícolas. Do mesmo modo, os indicadores faltantes obtiveram índices acima da linha base.

A produção integrada, animal-vegetal, realizada nessa propriedade contribui para a sustentabilidade, em razão da aplicação de recursos naturais, da utilização de mecanismos reguladores que substituem os insumos poluentes e do uso de instrumentos de monitoramento adequados, além de permitir a rastreabilidade do processo (Freitas et al., 2011). Considerando-se esses aspectos, é possível identificar a produção integrada animalvegetal como uma atividade economicamente viável e ambientalmente correta.

Dessa maneira, vê-se, portanto, que a unidade $C$ apresentou uma performance satisfatória na atividade de produção integrada de base ecológica, uma vez que o índice de impacto final esteve acima da linha base estipulada pelo Sistema APOIA-Novo Rural (Figura 4).

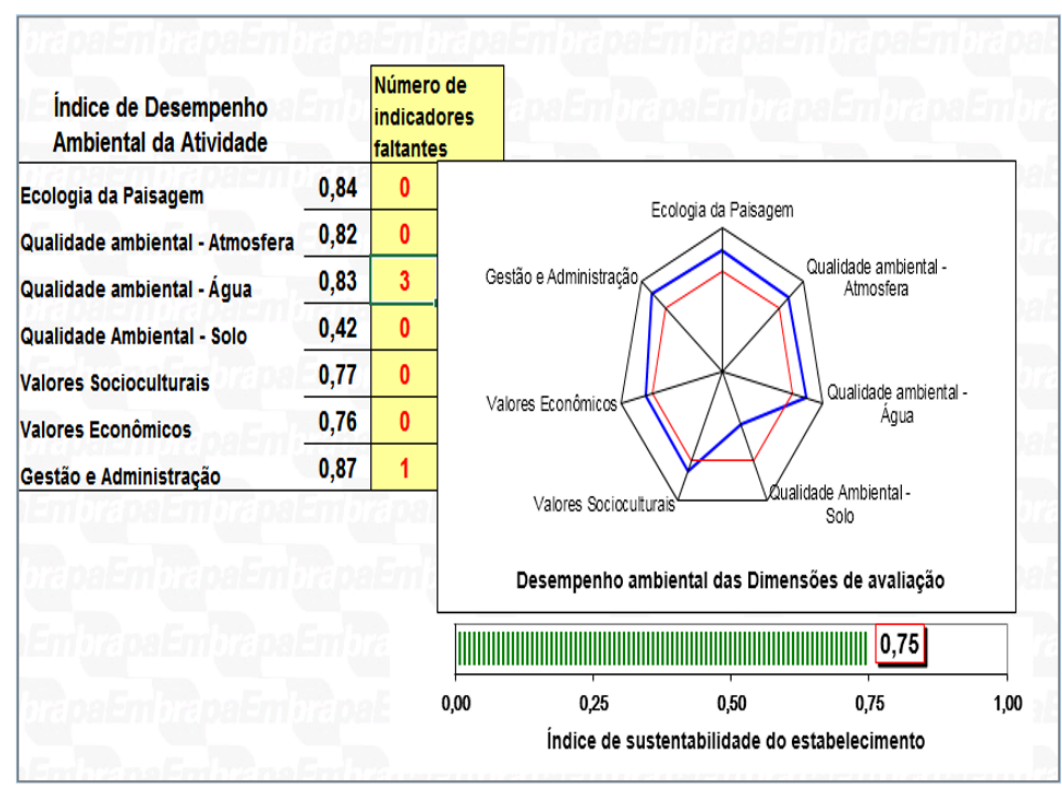

Figura 4 - AIA Final por meio do Sistema APOIA-Novo Rural, Unidade C. Fonte: Extraído pelos autores do Sistema APOIA-Novo Rural (2017). 


\section{Conclusões}

Os resultados obtidos com a aplicação do Sistema APOIA-Novo Rural nas três unidades permitiram concluir que a produção ecológica integrada trouxe impactos considerados como positivos para os estabelecimentos estudados, uma vez que o Índice de Sustentabilidade da Atividade de integração de produção animal-vegetal, de base ecológica, registrou valores acima da linha base $(0,70)$ para todas as propriedades $(A=0,75 ; B=0,72 ; C=0,75)$.

Destacaram-se os desempenhos positivos para as três unidades na dimensão Gestão e Administração (índices: $A=0,87 ; B=0,90 ; C=0,87$ ), respaldados pela forte dedicação dos responsáveis às atividades próprias do manejo integrado, pelos importantes relacionamentos institucionais e, sobretudo, pela gestão e pelo aproveitamento dos recursos da própria unidade.

Da mesma maneira, vale ressaltar a dimensão Valores Econômicos (índices: $A=0,80$; $\mathrm{B}=0,83 ; \mathrm{C}=0,76)$, a qual está relacionada, entre outros aspectos, com a diversidade das fontes de renda, a qualidade da moradia e o aumento do valor da propriedade.

Quanto às questões ambientais, é importante destacar o papel das três unidades (índices: $A=0,81 ; B=0,71 ; C=0,84$ ) na Dimensão Ecologia da Paisagem, resultado das boas condições nas áreas de habitats naturais, das condições apropriadas no manejo de animais, da existência de corredores ecológicos, entre outras ações.

O resultado global das propriedades, obtido com o Sistema APOIA-Novo Rural, ainda que tenha sido positivo, é proveniente de cinco dimensões, sendo que, na Qualidade ambiental Solo, não foram observados bons desempenhos em nenhuma das unidades (índices: $A=0,45$; $B=0,39 ; C=0,42$ ). Tal constatação ressalta a necessidade de que sejam adotadas tecnologias que favoreçam a fertilidade dos solos, com manejo orgânico, uma vez que esse desempenho inferior afetou a análise global de sustentabilidade.

Considera-se que a aplicação do Sistema APOIA-Novo Rural alcançou o seu objetivo de oferecer uma ferramenta de análise sistêmica, comparável e replicável pelo próprio proprietário. Contudo, avanços são necessários, uma vez que a diversidade produtiva animalvegetal é extensa e a metodologia de análise deve acompanhar a evolução das atividades no meio rural.

Sugerem-se novos estudos e pesquisas, incluindo novos dados primários e secundários, bem como a possibilidade de utilização de técnicas, como análise multivariada, acrescida de pesos e de grau de importância das variáveis inclusas neste modelo, enriquecendo a interpretação dos dados e auxiliando na identificação dos componentes agropecuários do sistema passíveis de incremento.

\section{Referências}

Abramovay, R. (1990). De camponeses à agricultores: paradigmas do capitalismo agrário em questão (Tese de doutorado). Instituto de Filosofia e Ciências Humanas, Universidade Estadual de Campinas.

Aguiar, A., Godinho, M., \& Costa, C. (2005). Produção integrada. Porto: Sociedade Portuguesa de Inovação.

Brasil. Secretaria Especial de Agricultura Familiar e do Desenvolvimento Agrário - SEAD. (2017). Brasil agroecológico: Plano Nacional de Agroecologia e Produção Orgânica (PLANAPO). Recuperado em 8 de abril de 2019, de http://www.mda.gov.br/planapo/

Brisola, M. V. (2001, julho). Operações na pecuária de corte: uma abordagem (eco) sistêmica. In Anais do IV Congresso Brasileiro de Administração Rural. Goiânia.

Buainain, A. (2006). Agricultura familiar, agroecologia e desenvolvimento sustentável: questões para debate. Brasília: IICA.

Campanhola, C., \& Valarini, P. J. (2001). A agricultura orgânica e seu potencial para o pequeno agricultor. Cadernos de Ciência \& Tecnologia, 18(3), 69-101.

Campanhola, C., Rodrigues, G. S., Valarini, P. J., Frighetto, R. T. S., Queiroz, J. F., Toledo, L. G., Ramos Filho, L. O., Rodrigues, I., \& Brombal, J. C. (2004). Avaliação do impacto ambiental de atividades do novo rural. In C. Campanhola \& J. G. Silva (Eds.), O novo rural brasileiro novas atividades rurais (pp. 279-306). Brasília: Embrapa Informação Tecnológica. 
Castro Neto, N., Denuzi, V. S. S., Rinaldi, R. N., \& Staduto, J. R. (2010). Produção orgânica: uma potencialidade estratégica para a agricultura familiar. Revista Percurso, 2(2), 73-95.

Cavalcanti, N., \& Maistro, M. (2015). A produção orgânica da agricultura familiar no Nordeste brasileiro e sua inserção no Programa de Aquisição de Alimentos. Cadernos de Agroecología, 10(3), 1-5.

Companhia de Planejamento do Distrito Federal - CODEPLAN. (2013). Pesquisa Metropolitana por Amostra de Domicílios (PMAD): Santo Antônio do Descoberto. Brasília. Recuperado em 08 de abril de 2019, de http://www.codeplan.df.gov.br/wp-content/uploads/2018/03/Santo-Antônio-doDescoberto-2013.pdf

Companhia de Planejamento do Distrito Federal - CODEPLAN. (2015). Agricultura familiar no Distrito Federal: dimensões e desafios. Brasília. Recuperado em 08 de abril de 2019, de http://www.codeplan.df.gov.br/wp-content/uploads/2018/02/Agricultura-Familiar-no-DFDimensões-e-Desafios.pdf

Empresa Brasileira de Pesquisa Agropecuária - EMBRAPA. (2012). Portfólio de projetos em sistemas de produção de base ecológica: documento síntese. Brasília: Comitê Gestor do Portfolio de Projetos em Sistemas de Base Ecológica.

Fonseca, M. F. A. (2005). Institucionalização do mercado de orgânicos no mundo e no Brasil: uma interpretação (Tese de doutorado). Instituto de Ciências Humanas e Sociais, Universidade Federal Rural do Rio de Janeiro.

Freire, A. G., Silveira, L., Melo, M. N., \& Nogueira, F. (2009). No inverno a gente planta, no verão a gente cria. In M. Lima (Ed.), Agriculturas: experiências em agroecologia: integração cultivos-criações (pp. 715). Rio de Janeiro: Fundação lleia.

Freitas, J., Braga Sobrinho, R., \& Viana, F. (2011). Guia para implementação do sistema de produção integrada de melão (Documentos, No. 141). Fortaleza: Embrapa Agroindústria Tropical.

Galharte, C. A. (2007). Avaliação de impactos ambientais da integração lavoura-pecuária: estudo de caso da inovação tecnológica da Embrapa (Dissertação de mestrado). Escola de Engenharia de São Carlos, Universidade de São Paulo.

González de Molina, M. (2004). Historia y médio ambiente. Morelia: Jitanjáfora.

Lima, M. (2009). Agriculturas: experiências em Agroecologia. Leisa Brasil, 6(2). Recuperado em 08 de abril de 2019, de http://aspta.org.br/wp-content/uploads/2011/05/Agriculturas_v6n2.pdf

Lutzenberger, J. (2001). O absurdo da agricultura. Estudos Avançados, 15(43), 61-74.

Macedo, M. C. M. (2009). Integração lavoura e pecuária: o estado da arte e inovações tecnológicas. Revista Brasileira de Zootecnia, 38(spe), 133-146.

Marzall, K., \& Almeida, J. (2000). Indicadores de sustentabilidade para agroecossistemas. Estado da arte limites e potencialidades de uma nova ferramenta para avaliar o desenvolvimento sustentável. Cadernos de Ciência \& Tecnologia, 17(1), 41-59.

Mazoyer, M., \& Roudart, L. (1998). História das agriculturas do mundo: do neolítico à crise contemporânea (J. L. Godinho, Trad.). Lisboa: Instituto Piaget.

Model, D., Esswein, D., Gallina, L. S., Teo, C. R. P. A., Nothafi, S. C. S., \& Busato, M. A. (2015). Ambiente e alimentação saudável: percepções e práticas de agricultores familiares. Campo-Território: Revista de Geografia Agrária, 10(21), 142-158.

Organización de las Naciones Unidas para la Alimentación y la Agricultura - FAO. (2003). Agricultura orgánica, ambiente y seguridad alimentaria. Roma. Recuperado em 08 de abril de 2019, de http://www.fao.org/docrep/005/y4137s/y4137s00.htm

Organización de las Naciones Unidas para la Alimentación y la Agricultura - FAO. (2014). Pérdidas y desperdicio de alimentos en el mundo: alcance, causas y prevención. Roma. Recuperado em 08 de abril de 2019, de https://www.derechoalimentacion.org/sites/default/files/pdf-documentos/HLPEReport-8_Web_0.pdf

Rezende, C. L. (2005). O agronegócio dos alimentos orgânicos (Dissertação de mestrado). MBA Fundance.

Rodrigues, G. (2011). Indicadores de sustentabilidade e boas práticas para gestão ambiental na aquicultura. In I Simpósio em Produção de Organismos Aquáticos e Desenvolvimento Sustentável. Rio de Janeiro, Brasil. 
Rodrigues, G. S., Almeida Buschinelli, C. C., Santana, D. P., da Silva, A. G., \& Pastrello, B. M. C. (2008). Avaliação ambiental de práticas de manejo sítio específico aplicadas à produção de grãos na região de Rio Verde (GO). Revista Brasileira de Agrociência, 14, 58-66.

Rodrigues, G. S., Campanhola, C., \& Kitamura, P. C. (2003). Avaliação de impacto ambiental da inovação tecnológica agropecuária: AMBITEC-AGRO (Documentos, No. 34). Jaguariúna: Embrapa Meio Ambiente.

Rodrigues, G. S., Campanhola, C., Rodrigues, I., Friguetto, R. T. S., Valarini, P., \& Ramos Filho, L. O. (2006). Gestão Ambiental de atividades rurais: estudo de caso em agroturismo e agricultura orgânica. Agricultura em São Paulo, 53, 17-31.

Rodrigues, G., \& Campanhola, C. (2003). Sistema integrado de avaliação de impacto ambiental aplicado a atividades do Novo Rural. Pesquisa Agropecuária Brasileira, 38(4), 445-451.

Serrano, J. (2005). El problema de los cultivos transgénicos en América Latina: una "nueva" revolución verde. Entorno Geográfico, 3, 93-120. Recuperado em 08 de abril de 2019, de http://web.ua.es/es/giecryal/documentos/documentos839/docs/cultivostransgenicos.pdf

Soares, J. P. G., Leal, M. A., Salman, A. K. D., \& López, G. F. Z. (2018). Manejo da fertilidade de solos em áreas de pastagem orgânica. In I. M. Cardoso \& C. Favero (Ed.), Solos e agroecologia (Coleção Transição Agroecologia, No. 4, pp. 271-305). Brasília: EMBRAPA.

Soares, J. P. G., Neves, D. L., \& Carvalho, J. M. (2014). Produção de carne bovina em sistema orgânico: desafios e tecnologias para um mercado em expansão. In R. L. Oliveira \& M. A. A. F. Barbosa (Eds.), Bovinocultura de corte: desafios e tecnologias (2. ed., pp. 701-725). Salvador: EDUFBA.

Tosetto, E., Cardoso, I., \& Furtado, S. A. (2013). importância dos animais nas propriedades familiares rurais agroecológicas. Revista Brasileira de Agroecologia, 8, 12-25. Recuperado em 08 de abril de 2019, de http://orgprints.org/26046/1/Toseto_A\%20importancia\%20dos\%20Animais.pdf

Recebido: Abril 08, 2019.

Aceito: Fevereiro 15, 2021

JEL Classification: 013, O35, Q51, Q55, Q57 